\title{
The association between relationship markers of sexual orientation and suicide: Denmark, 1990-2001
}

\author{
Robin M. Mathy $\cdot$ Susan D. Cochran • \\ Jorn Olsen • Vickie M. Mays
}

Received: 28 June 2009/ Accepted: 9 December 2009/Published online: 24 December 2009

(C) The Author(s) 2009. This article is published with open access at Springerlink.com

\begin{abstract}
Objective Minority sexual orientation has been repeatedly linked to elevated rates of suicide attempts. Whether this translates into greater risk for suicide mortality is unclear. We investigated sexual orientation-related differences in suicide mortality in Denmark during the initial 12year period following legalization of same-sex registered domestic partnerships (RDPs).

Method Using data from death certificates issued between 1990 and 2001 and population estimates from the Danish census, we estimated suicide mortality risk among individuals classified into one of three marital/cohabitation statuses: current/formerly in same-sex RDPs; current/formerly heterosexually married; or never married/registered. Results Risk for suicide mortality was associated with this proxy indicator of sexual orientation, but only significantly among men. The estimated age-adjusted suicide mortality risk for RDP men was nearly eight times greater than for men with positive histories of heterosexual marriage and nearly twice as high for men who had never married.
\end{abstract}

R. M. Mathy

Department of Health Sciences and Kellogg College,

University of Oxford, Oxford, UK

S. D. Cochran $(\bowtie) \cdot$ J. Olsen

UCLA School of Public Health, University of California,

Los Angeles, USA

e-mail: cochran@ucla.edu

V. M. Mays

UCLA Center for Research, Education, Training and Strategic

Communications on Minority Health Disparities,

University of California, Los Angeles, USA

e-mail: mays@ucla.edu
Conclusions Suicide risk appears greatly elevated for men in same-sex partnerships in Denmark. To what extent this is true for similar gay and bisexual men who are not in such relationships is unknown, but these findings call for targeted suicide prevention programs aimed at reducing suicide risk among gay and bisexual men.

Keywords Suicide - Homosexuality · Gay · Lesbian · Mortality

\section{Introduction}

In recent years, accumulating research findings have convincingly shown that persons with self-reported markers of minority sexual orientation (e.g., histories of same-gender sexual partners and/or identification as lesbian, gay, or bisexual), as compared to others without such markers, are at increased risk for suicide attempts [1-17]. Few studies [18-20], however, have attempted to answer the fundamental question: are gay, lesbian, and bisexual individuals more likely than heterosexuals to die by suicide?

Considerable debate exists within the field as to whether a greater propensity for suicide attempts among lesbian, gay, and bisexual individuals translates into an actual greater risk for suicide mortality [19, 21, 22]. One reason for the uncertainty is that individual risk factors for suicide attempts are not entirely consistent with individual risk factors for completed suicide. For example, while women, in general, are more likely to attempt suicide, men are more likely to die by suicide [23]. A second reason is that many of these recent studies [5, 6, 8, 11-14] examining suicide attempt risk among lesbians, gay men, and bisexual individuals classified sexual orientation solely on the basis of reports of same-gender sexual partners. This group of 
individuals includes a large proportion who, if asked, would actually have identified as heterosexual [21]. This raises doubts as to whether it is minority sexual orientation identity per se that is linked to the observed greater risk for suicide attempts as opposed to other individual characteristics, such as a propensity for sexual experimentation [24].

In the current study, we investigate evidence for an association between sexual orientation and suicide mortality using 12 years of population-based data from Denmark. Beginning in 1990, same-gender partners were legally able to register their partnerships with the Danish government. Since that time, death certificates tracking marital status have reflected the registered domestic partner (RDP) category. A recent study [25] of RDP status in Denmark found somewhat elevated all-cause mortality risk in early years of RDP status in Danish population, particularly among men in RDP relationships. One earlier report [26], using data from only 1994-1997, found tentative evidence of a link between RDP status and risk for suicide mortality, but the very small sample size precluded examination of possible gender differences. We hypothesize that individuals in same-sex partnerships will evidence greater risk for suicide mortality as compared to married or formerly married individuals, reflecting a hypothesized greater risk associated with minority sexual orientation [1$6,8-15,17]$. Given that predictors of suicide vary between men and women [23, 27], we anticipate, as well, that the association between sexual orientation and completed suicide might well vary between men and women.

\section{Methods}

Source and nature of the data

Suicide mortality data for the years 1990-2001 were obtained from the Danish National Board of Health. Prior to 1994 , the Registry coded suicide as a primary cause of death using International Classification of Diseases (ICD8) codes E950-E959 [28]. From 1994 on, ICD-10 [29] classification categories X60-X84 were used. Each suicide case was further specified by year of death (1990-2001), age at death (18-40 years, 41-65 years, and 66 years or older), gender (male, female), and marital status at time of death (single, married, divorced, widowed, registered partner, dissolved partner, or surviving partner). Because only same-sex partners are eligible for partnership status in Denmark, we recoded marital status into one of three categories: (1) current or past married status reflecting indirect evidence of a heterosexual sexual orientation (married, divorced, widowed), (2) current or past RDP status reflecting indirect evidence of a homosexual sexual orientation (registered partner, dissolved partner, surviving partner), and (3) never married, which provided no information, direct or otherwise, as to possible sexual orientation.

To estimate the number of individuals at risk annually for suicide-related mortality, we obtained census data from the Statistics Denmark website (http://www.dst.dk) to match the incident cases described above by year of death, age group, gender, and marital status. Midyear census counts that allowed matching to the age, gender, and relationship status categories described above were available only for years 1993-2001. However, fully matchable data were available for the population size as of January 1 for all years. For years 1990-1992, we estimated the midyear population counts by averaging the January 1 population sizes of the two contiguous years both before and after the midyear point of interest. Over the years, the number of current and formerly registered persons increased substantially.

For men, 255 were classified as current or former RDP in 1990 increasing to 2,348 in the midyear count of 2001; for women, the numbers increased from 862 to 3,521 across the same time span.

\section{Statistical analysis}

Analyses were conducted using Stata 9 [30]. Incident suicide mortality rates per 100,000 person-years were calculated using midyear population estimates. Both crude and age-standardized incidence rates are reported separately by gender, given the well-known robust gender difference in risk for death by suicide [27]. Age standardization was done using direct methods [31]. Additional analyses used Poisson regression methods to estimate suicide mortality risk ratios for individuals varying in relationship histories. Married and formerly married persons were treated as the referent group. These analyses were conducted twice using both midyear and January 1 population sizes due to potentially greater accuracy in the latter census counts. Because findings led to identical conclusions, we report in the text only the results from analyses using estimates of midyear counts. For overall multivariate estimates, we treated age, year of death, and gender as potential confounders; for genderspecific multivariate estimates, potential confounders included age and year of death. Mortality risk ratios and their 95\% confidence intervals (CI) are reported in the tables. The statistical significance of study findings is evaluated at the $p<0.05$ level. This study received formal IRB approval from UCLA. Our use of suicide mortality case data was approved by the Danish Data Inspectorate and the Board of Health's Expert Committee. According to Danish Law, IRB approval is not needed for research on anonymous data. 


\section{Results}

During the 12-year period of interest, risk for death from causes associated with suicide varied by gender, age, and relationship status in Denmark (see Table 1). Despite the relatively small numbers of individuals with histories of being in RDP relationships, the rate of death from suicide among men in this subpopulation greatly exceeded that of either never married men or men who were either currently or formerly heterosexually married. In contrast, suicide mortality risk among women with positive histories of RDP status did not appear to vary significantly from those of other women regardless of their marital status. While never married women evidenced a lower suicide mortality risk than current or formerly married women as a group, never married women were at greater suicide mortality risk when compared to currently married women alone (age-standardized mortality rate $=8.9,95 \%$ CI: 8.4-9.4) .

Estimates of mortality risk ratios suggest that both never married individuals and those with cohabiting relationship histories indicative of being lesbian, gay, or bisexual were more likely to die by suicide than married or formerly married persons, after adjusting for age, gender, and year of death (see Table 2). Indeed, the risk for suicide among the subpopulation of individuals likely to be lesbian, gay, or bisexual was more than four times greater than that seen among currently or formerly married persons. However, this increased risk was concentrated almost exclusively among men. When analyses were restricted to comparisons among men, the risk for death by suicide among men with RDP backgrounds was estimated as more than eight times greater than that seen among married or formerly married men. In contrast, being never married was associated with a far smaller increase in risk for suicide among men. Among women, being never married was associated with a lower risk of suicide compared to being currently or formerly married, but having a positive RDP history appeared to have only a modest and statistically nonsignificant positive effect on suicide mortality risk.

Table 1 Age-specific mortality rates due to suicide in Denmark, 1990-2001, by age, gender, and heterosexual and registered partnership relationship status

\begin{tabular}{|c|c|c|c|c|c|c|c|c|}
\hline \multirow{2}{*}{$\begin{array}{l}\text { Relationship status }{ }^{\mathrm{a}} \\
\text { and age at death }\end{array}$} & \multicolumn{4}{|l|}{ Men } & \multicolumn{4}{|l|}{ Women } \\
\hline & Suicides & $\begin{array}{l}\text { Estimated } \\
\text { person-years }\end{array}$ & $\begin{array}{l}\text { Crude } \\
\text { mortality } \\
\text { rate }^{c}\end{array}$ & $\begin{array}{l}\text { Age-standardized } \\
\text { mortality rate }\end{array}$ & Suicides & $\begin{array}{l}\text { Estimated } \\
\text { person-years }\end{array}$ & $\begin{array}{l}\text { Crude } \\
\text { mortality } \\
\text { rate }^{c}\end{array}$ & $\begin{array}{l}\text { Age-standardized } \\
\text { mortality rate }\end{array}$ \\
\hline \multicolumn{9}{|c|}{ Current or past married status } \\
\hline $18-40$ years & 679 & $4,663,558$ & 14.6 & & 294 & $3,664,260$ & 8.0 & \\
\hline $41-65$ years & 2,754 & $9,028,159$ & 30.5 & & 1,504 & $8,506,873$ & 17.7 & \\
\hline 66 and older & 1,673 & $4,941,082$ & 33.9 & & 1,149 & $3,430,547$ & 33.5 & \\
\hline All & 5,106 & $18,632,799$ & 27.4 & $24.7(24.0-25.4)$ & 2,947 & $15,601,680$ & 18.9 & $15.8(15.2-16.4)$ \\
\hline \multicolumn{9}{|l|}{ Never married } \\
\hline $18-40$ years & 1,657 & $5,624,470$ & 29.5 & & 356 & $7,070,539$ & 5.0 & \\
\hline $41-65$ years & 643 & 729,905 & 88.1 & & 182 & $1,276,503$ & 14.3 & \\
\hline 66 and older & 207 & 367,461 & 56.3 & & 72 & 262,331 & 27.4 & \\
\hline All & 2,507 & $6,721,836$ & 37.3 & $57.6(54.5-60.8)$ & 610 & $8,609,373$ & 7.1 & $12.2(10.9-13.5)$ \\
\hline \multicolumn{9}{|c|}{ Current or past registered partnership status } \\
\hline $18-40$ years & 8 & 7,334 & 109.1 & & 3 & 12,371 & 24.3 & \\
\hline $41-65$ years & 14 & 6,751 & 207.4 & & 3 & 14,311 & 21.0 & \\
\hline 66 and older & 2 & 458 & 436.7 & & 0 & 1,635 & 0.0 & \\
\hline All & 24 & 14,543 & 165.0 & $215.5(78.9-352.1)$ & 6 & 28,317 & 21.2 & $19.2(3.7-34.7)$ \\
\hline All adults & 7,637 & $25,369,178$ & 30.1 & & 3,563 & $24,239,370$ & 14.7 & \\
\hline
\end{tabular}

Suicide mortality data provided by Danish Mortality Registry. Deaths in 1990-1993 were coded according to ICD-8 criteria [28] and those in 1994-2001 according to ICD-10 criteria [29]. Population counts were obtained from the Statistics Denmark website (http://www.dst.dk)

${ }^{a}$ Persons coded into one of three categories at time of death: single, evidence of heterosexual status (married, widowed, divorced, separated), or evidence of same-sex relationship (registered partner, surviving partner, member of a dissolved partnership)

b Person-years estimated from midyear population census counts for the years 1993-2001. For the years 1990-1992, the midyear population is estimated as the average of January 1 population counts for the year in question and the January 1 population count for the subsequent year

${ }^{c}$ Estimated per 100,000 person-years

${ }^{d}$ Standardized to the total population within each gender separately. Numbers in parentheses are $95 \%$ CI for the estimate 
Table 2 Suicide incidence risk ratios by gender and relationship status, Denmark, 1990-2001

\begin{tabular}{|c|c|c|c|c|c|c|}
\hline \multirow[t]{2}{*}{ Relationship Status } & \multicolumn{2}{|l|}{ Total } & \multicolumn{2}{|l|}{ Men } & \multicolumn{2}{|l|}{ Women } \\
\hline & $\begin{array}{l}\text { Crude } \\
\text { analysis }\end{array}$ & $\begin{array}{l}\text { Adjusted } \\
\text { analysis }^{\mathrm{a}}\end{array}$ & $\begin{array}{l}\text { Crude } \\
\text { analysis }\end{array}$ & $\begin{array}{l}\text { Adjusted } \\
\text { analysis }^{\mathrm{b}}\end{array}$ & $\begin{array}{l}\text { Crude } \\
\text { analysis }\end{array}$ & $\begin{array}{l}\text { Adjusted } \\
\text { analysis }^{\text {b }}\end{array}$ \\
\hline Current or past married status & 1.00 & 1.00 & 1.00 & 1.00 & 1.00 & 1.00 \\
\hline Never married & $0.86(0.83-0.90)$ & $1.42(1.35-1.49)$ & $1.36(1.30-1.43)$ & $1.92(1.82-2.03)$ & $0.38(0.34-0.41)$ & $0.69(0.63-0.76)$ \\
\hline $\begin{array}{l}\text { Current or past registered } \\
\text { partnership status }\end{array}$ & $2.98(2.08-4.26)$ & $4.76(3.32-6.81)$ & $6.02(4.03-8.99)$ & $8.19(5.48-12.24)$ & $1.12(0.50-2.50)$ & $1.65(0.74-3.68)$ \\
\hline
\end{tabular}

Partial results of Poisson regression analyses are shown. Numbers in parentheses are 95\% CI

a Adjusted for gender, age category, and year of death

b Adjusted for age category and year of death

\section{Discussion}

In Denmark, as well as in the United States, an individual's sexual orientation identity is not recorded in death certificates. This greatly limits routine administrative surveillance of suicide mortality risk among lesbian, gay, and bisexual individuals, a subpopulation with known elevated risk for suicide attempts $[1-6,8-15]$. This administrative limitation also affects the current study: we could not directly measure sexual orientation identity, but were forced to rely on registered domestic partner status as a proxy for minority sexual orientation identity. Nevertheless, our findings substantiate concerns that the elevation in risk for suicide attempts observed internationally among homosexual and bisexual men $[5,6,8,10,11,13,14]$ is paralleled by a greatly higher risk for suicide mortality among men who are likely to be gay or bisexual. Comparisons of suicide mortality rates between Danish men with positive RDP histories versus those with positive histories of heterosexual marriage revealed an eightfold greater age-adjusted risk for death by suicide among the RDP group. While the numbers of incident suicides in Danish men in RDP relationships were small, reducing precision, this elevation in risk nonetheless appears to be present across the lifespan. Whether this finding extends to all men with minority sexual orientation is currently unanswerable given the limits of available mortality data. However, our findings support longstanding concerns that suicide is a critical mental health issue for the gay men and bisexual men $[2,32]$.

In marked contrast, we failed to observe a similar elevation in risk for suicide mortality among women who are likely to be lesbian or bisexual. The reason why sexual orientation appears linked to suicide mortality in men, but not to the same extent in women, with histories of being in same-sex registered domestic partnerships (RDPs) is unclear. Both gay men and lesbians in same-gender relationships experience considerable cultural antipathy toward same-sex marriage and domestic partnerships, even where they are legally endorsed [33]. While attitudes toward homosexuality are more tolerant in Northern Europe than in the United States [34], heterosexual marriage remains the ideal in Denmark [35]. Both lesbians and gay men also frequently experience anti-gay stigma and consequent adversity in their daily lives $[36,37]$, the presumed mechanism that leads to the somewhat elevated risk for psychological morbidity that has been observed in this population [21]. In particular, both lesbians and gay men compared to their heterosexual counterparts are at higher risk for major depression [38], an important risk factor for completed suicide [39]. And though the evidence for women is somewhat less compelling, it appears that both lesbians and gay men are at higher risk for lifetime histories of suicide attempts [1-6, 8-15], also a known risk factor for suicide mortality [40].

But there are other ways in which the lives of lesbians and gay men differ and it may be these factors that are more closely linked to suicide mortality risk. One obvious difference is the impact of the HIV epidemic on gay men's health [41]. Although the estimated prevalence of HIV infection among men who have sex with men in Denmark (4.8\%) [42] is far lower than estimates in the United States, it may be that some of the increase in suicide risk results from gay men's experiences with HIV disease either personally or among their partners and friendship networks $[43,44]$. Further, a recent study [25] of all-cause mortality in Denmark found a substantial reduction in mortality risk among men in RDP relationships after the introduction of highly active anti-retroviral therapy (HAART). Future studies might profitably examine the co-occurrence of HIV infection and suicide mortality. Important in this investigation would be a distinction between suicides from before and after HAART introduction, a distinction that may become clearer with additional years of mortality experiences among individuals in RDP relationships. At this junction, however, the gender differences in suicide mortality risk among lesbians and gay men remain unexplained. 
We also observed a higher risk for suicide among never married men compared to current or formerly married men but a lower risk for suicide among never married women when compared to current/formerly married women. Never married women, however, were at higher suicide mortality risk than currently married women, consistent with other European studies [45, 46]. Our findings were due to the higher suicide mortality risk among formerly married women, including widowed individuals who represent a well-known higher risk group for suicide [47].

Results observed here should be considered in the context of four potential study limitations. First, as mentioned earlier, we did not directly measure sexual orientation, but rather used registered partner status as a proxy for minority sexual orientation identity. One consequence is the exclusion of individuals under age 18, the legal age in Denmark for entering RDP status. Also, to the extent that individuals in registered same-sex partnerships differ from lesbian, gay, and bisexual individuals who are not, we may have under or overestimated suicide-related mortality in this subpopulation. Currently, the proportion of same-sex couples in Denmark that legally register their relationship is unknown, but estimates from the United States suggest that only a minority of lesbian, gay, and bisexual individuals, especially men, live in a cohabiting same-sex relationship [48], and the extent to which these couples are legally registered with governmental agencies when permitted by law is unknown but presumably a much smaller subset of such persons, especially among men [49]. Married individuals, in general, have the lowest risk for suicide mortality [8]. If one assumes that similar protective properties endemic to marriage extend to same-sex couples [25, 50, 51], then we would anticipate that the findings reported here are most likely an underestimate rather than an overestimate of suicide mortality risk among lesbian, gay, and bisexual adults as a whole.

Second, recent findings for all causes of death in Denmark [25] show that both men and women in registered same-sex partners have a significantly elevated mortality risk when compared to married individuals, but only in the initial years following registration. This finding has been interpreted as suggestive that individuals who are severely ill will be more likely to register, thus biasing estimates in the direction of showing greater mortality linked to sexual orientation where such differences do not actually exist [25]. But whether this is true for suicide as a cause of death is unclear. Further, the assertion of differential selection into RDP status conditional on mortality risk is based on very small sample sizes, particularly for long-term relationships where mortality rates generally remained elevated but did not achieve statistical significance. Low statistical power may have created this pattern of results. Given the newness of the institutionalization of RDPs, it will take several years of accumulating experience to clarify whether selection is a reasonable hypothesis for explaining what was observed in the current study.

Third, errors of misclassification in the allocation of primary cause of death to suicide are always a concern [52]. If these were confounded in some way with registered partner status then this might serve to inflate or deflate our estimates of the relative risk of suicide mortality in this subpopulation. Because we observed elevation in rates among men, but not women, in registered partnerships, we are reassured that this bias, if it exists, was minimal. However, future studies of method of self-injury might clarify the import of this concern.

Finally, we limited our analysis to suicide as a primary cause of death in a single country and did so with minimal information about the deceased individuals. It is possible, future studies that examine suicide as both a primary or contributing cause of death (multiple cause mortality) or suicide mortality in other geographic regions may observe somewhat different results. Also future studies might gainfully explore demographic and behavioral characteristics of gay and bisexual suicide completers.

With the emergence of new administrative forms of relationship status in various states within the United States and in other countries internationally where same-sex marriage or domestic partnerships have been legalized, scientists have a unique opportunity to track the health and mental health correlates of sexual orientation using these administrative databases and to do so over time. In this study, we have used administrative records from Denmark to uncover an unrecognized, but widely anticipated [1-6, 8-15], elevated risk for suicide-related mortality among adult gay and bisexual men.

These results call strongly for the development of suicide prevention programs for gay and bisexual men that target men's concerns across the lifespan. They also underscore the importance of integrating into our surveillance systems thoughtful measurement of both mental health indicators, including suicide-related morbidity and mortality, and markers of sexual orientation. As an example, currently the Centers for Disease Control and Prevention (CDC) in the United States assesses homosexual behavior in its surveillance of HIV and other sexual transmitted diseases [53]. This is an effort to reduce morbidity and mortality among gay and bisexual men, a vulnerable population for acquiring sexually transmitted diseases. But CDC tracking of suicide mortality is accomplished through the National Violent Death Reporting System [54] which does not measure markers of sexual orientation, though it does provide information on other social statuses readily available in administrative records such as age, gender, marital status, and race/ethnicity. Better integration of data sources, including use of 
domestic partnership registries and information on the sexual orientation of marriages in those states and countries where same-sex marriage is legal, might prove beneficial to reducing mental health disparities linked to minority sexual orientation. To date, in the United States, only gay and lesbian adolescents have been labeled as a vulnerable population for suicide morbidity by the US Public Health Service [55]. Our findings strongly suggest a broadening of that focus to adult gay men, at a minimum.

Acknowledgments This research was funded by grants from the National Institute of Drug Abuse (DA 15539, DA 20826) and the National Center for Minority Health and Health Disparities (MD 000508)

Open Access This article is distributed under the terms of the Creative Commons Attribution Noncommercial License which permits any noncommercial use, distribution, and reproduction in any medium, provided the original author(s) and source are credited.

\section{References}

1. Faulkner AH, Cranston K (1998) Correlates of same-sex sexual behavior in a random sample of Massachusetts high school students. Am J Public Health 88:262-266

2. Remafedi G, French S, Story M, Resnick MD, Blum R (1998) The relationship between suicide risk and sexual orientation: results of a population-based study. Am J Public Health 88:57-60

3. Fergusson DM, Horwood LJ, Beautrais AL (1999) Is sexual orientation related to mental health problems and suicidality in young people? Arch Gen Psychiatry 56:876-880

4. Garofalo R, Wolf RC, Wissow LS, Woods ER, Goodman E (1999) Sexual orientation and risk of suicide attempts among a representative sample of youth. Arch Pediatr Adolesc Med 153:487-493

5. Herrell R, Goldberg J, True WR, Ramakrishnan V, Lyons M, Eisen S, Tsuang MT (1999) Sexual orientation and suicidality: a co-twin control study in adult men. Arch Gen Psychiatry 56:867874

6. Cochran SD, Mays VM (2000) Lifetime prevalence of suicidal symptoms and affective disorders among men reporting same-sex sexual partners: results from the NHANES III. Am J Public Health 90:573-578

7. van Heeringen $C$, Vincke $J$ (2000) Suicidal acts and ideation in homosexual and bisexual young people: a study of prevalence and risk factors. Soc Psychiatry Psychiatr Epidemiol 35:494499

8. Gilman SE, Cochran SD, Mays VM, Hughes M, Ostrow D, Kessler RC (2001) Risk of psychiatric disorders among individuals reporting same-sex sexual partners in the National Comorbidity Survey. Am J Public Health 91:933-939

9. Russell ST, Joyner K (2001) Adolescent sexual orientation and suicide risk: evidence from a national study. Am J Public Health 91:1276-1281

10. Balsam KF, Beauchaine TP, Mickey RM, Rothblum ED (2005) Mental health of lesbian, gay, bisexual, and heterosexual siblings: effects of gender, sexual orientation, and family. J Abnorm Psych 114:471-476

11. de Graaf R, Sandfort TG, ten Have M (2006) Suicidality and sexual orientation: differences between men and women in a general population-based sample from the Netherlands. Arch Sex Behav 35:253-262

12. Eisenberg ME, Resnick MD (2006) Suicidality among gay, lesbian and bisexual youth: the role of protective factors. J Adol Health 39:662-668

13. Lhomond B, Saurel-Cubizolles MJ (2006) Violence against women and suicide risk: the neglected impact of same-sex sexual behaviour. Soc Sci Med 62:2002-2013

14. Cochran SD, Mays VM, Alegria M, Ortega A, Takeuchi DT (2007) Mental health and substance use disorders among Latino and Asian American lesbian, gay, and bisexual adults. J Consult Clin Psych 75:785-794

15. Silenzio VM, Pena JB, Duberstein PR, Cerel J, Knox KL (2007) Sexual orientation and risk factors for suicidal ideation and suicide attempts among adolescents and young adults. Am J Public Health 97:2017-2019

16. Hidaka Y, Operario D, Takenaka M, Omori S, Ichikawa S, Shirasaka T (2008) Attempted suicide and associated risk factors among youth in urban Japan. Soc Psychiatry Psychiatr Epidemiol 43:752-757

17. King M, Semlyen J, Tai SS, Killaspy H, Osborn D, Popelyuk D, Nazareth I (2008) A systematic review of mental disorder, suicide, and deliberate self harm in lesbian, gay and bisexual people. BMC Psychiatry 8:70

18. Martin RL, Cloninger CR, Guze SB, Clayton PJ (1985) Mortality in a follow-up of 500 psychiatric outpatients. II. Cause-specific mortality. Arch Gen Psychiatry 42:58-66

19. Shaffer D, Fisher P, Hicks RH, Parides M, Gould M (1995) Sexual orientation in adolescents who commit suicide. Suicide Life Threat Behav 25(1):64-71

20. Mathy RM (2004) Suicide and sexual orientation. Br J Psychiatr 184:361-362

21. Cochran SD (2001) Emerging issues in research on lesbians' and gay men's mental health: does sexual orientation really matter? Am Psychol 56:931-947

22. Savin-Williams RC, Ream GL (2003) Suicide attempts among sexual-minority male youth. J Clin Child Adolesc Psychol 32:509-522

23. Oquendo MA, Bongiovi-Garcia ME, Galfalvy H, Goldberg PH, Grunebaum MF, Burke AK, Mann JJ (2007) Sex differences in clinical predictors of suicidal acts after major depression: a prospective study. Am J Psychiatry 164:134-141

24. Bailey JM (1999) Homosexuality and mental illness. Arch Gen Psychiatry 56:883-884

25. Frisch M, Bronnum-Hansen H (2009) Mortality among men and women in same-sex marriage: a national cohort study of 8333 Danes. Am J Pub Health 99:133-137

26. Qin P, Agerbo E, Mortensen PB (2003) Suicide risk in relation to socioeconomic, demographic, psychiatric, and familial factors: a national register-based study of all suicides in Denmark, 19811997. Am J Psychiatry 160:765-772

27. Diekstra RF (1993) The epidemiology of suicide and parasuicide. Acta Psychiatr Scand Sup 371:9-20

28. WHO (1967) Manual of the International Classification of Diseases (ICD-8), 8th revision. World Health Organization, Geneva

29. WHO (1992) The ICD-10 Classification of Mental and Behavioral Disorders (ICD-10), 10th revision. World Health Organization, Geneva

30. StataCorp (2005) Stata Statistical Software: Release 9. StataCorp LP, College Station, TX

31. Rothman K, Greenland S (1998) Modern epidemiology, 2nd edn. Lippincott-Raven Publishers, Philadelphia, PA

32. Paul JP, Catania J, Pollack L, Moskowitz J, Canchola J, Mills T, Binson D, Stall R (2002) Suicide attempts among gay and bisexual men: lifetime prevalence and antecedents. Am J Public Health 92:1338-1345 
33. Herek GM (2006) Legal recognition of same-sex relationships in the United States: a social science perspective. Am Psychol 61:607-621

34. Fish E (2005) The road to recognition: a global perspective on gay marriage. Harvard Intl Rev 27:32-34

35. Frisch M, Hviid A (2006) Childhood family correlates of heterosexual and homosexual marriages: a national cohort study of two million Danes. Arch Sex Behav 35:533-547

36. Mays VM, Cochran SD (2001) Mental health correlates of perceived discrimination among lesbian, gay, and bisexual adults in the United States. Am J Public Health 91:1869-1876

37. Meyer IH (2003) Prejudice, social stress, and mental health in lesbian, gay, and bisexual populations: conceptual issues and research evidence. Psychol Bull 129:674-697

38. Cochran SD, Mays VM (2009) Burden of psychiatric morbidity among lesbian, gay, and bisexual individuals in the California Quality of Life Survey. J Abnorm Psychol 118:647-658

39. Chan SS, Chiu HF, Chen EY, Chan WS, Wong PW, Chan CL, Law YW, Yip PS (2009) Population-attributable risk of suicide conferred by axis I psychiatric diagnoses in a Hong Kong Chinese population. Psychiatr Serv 60:1135-1138

40. Stoelb M, Chiriboga J (1998) A process model for assessing adolescent risk for suicide. J Adolesc 21:359-370

41. Cochran SD, Mays VM (2007) Physical health complaints among lesbians, gay men, and bisexual and homosexually experienced heterosexual individuals: results from the California Quality of Life Survey. Am J Public Health 97:2048-2055

42. Smith E (2003) HIV/AIDS surveillance in Denmark: the challenges ahead. J Acquir Immune Defic Syndr 32(Suppl 1):S33S38

43. Cochand P, Bovet P (1998) HIV infection and suicide risk: an epidemiological inquiry among male homosexuals in Switzerland. Soc Psychiatry Psychiatr Epidemiol 33:230-234
44. Starace F, Sherr L (1998) Suicidal behaviours, euthanasia and AIDS. AIDS 12:339-347

45. Yip PS, Thorburn J (2004) Marital status and the risk of suicide: experience from England and Wales, 1982-1996. Psychol Rep 94:401-407

46. Corcoran P, Nagar A (2009) Suicide and marital status in Northern Ireland. Soc Psychiat Epidemiol. doi: 10.1007/s00127-009-0120-7

47. Luoma JB, Pearson JL (2002) Suicide and marital status in the United States, 1991-1996: is widowhood a risk factor? Am J Public Health 92:1518-1522

48. Black D, Gates G, Sanders S, Taylor L (2000) Demographics of the gay and lesbian population in the United States: evidence from available systematic data sources. Demography 37:139-154

49. Carpenter C, Gates GJ (2008) Gay and lesbian partnership: evidence from California. Demography 45:573-590

50. Peplau LA, Fingerhut AW (2007) The close relationships of Lesbians and gay men. Ann Rev Psychol 58:405-424

51. Wienke C, Hill GJ (2009) Does the "Marriage Benefit" extend to partners in gay and lesbian relationships? Evidence from a random sample of sexually active adults. J Fam Issues 30:259-289

52. Rockett IR, Thomas BM (1999) Reliability and sensitivity of suicide certification in higher-income countries. Suicide Life Threat Behav 29:141-149

53. Allen DR, Finlayson T, Abdul-Quader A, Lansky A (2009) The role of formative research in the National HIV Behavioral Surveillance System. Public Health Rep 124:26-33

54. Karch DL, Dahlberg LL, Patel N, Davis TW, Logan JE, Hill HA, Ortega L (2009) Surveillance for violent deaths-national violent death reporting system, 16 States, 2006. MMWR Surveill Summ $58: 1-44$

55. Public Health Service US (1999) The Surgeon General's call to action to prevent suicide. Washington, DC 